\title{
Ninety Days and In-Hospital Mortality after Gastrointestinal and Hepatopancreatic Biliary Surgery- A Case Series Analysis.
}

bhavin bhuendra vasavada ( $\nabla$ drbhavin.liversurgeon@gmail.com )

shalby hospitals https://orcid.org/0000-0003-0502-6499

Hardik patel

Shalby Hospitals

\section{Research Article}

Keywords: mortality, gastrointestinal surgery, hepatopancreatic biliary surgery, hpb surgery

Posted Date: September 23rd, 2021

DOl: https://doi.org/10.21203/rs.3.rs-900976/v1

License: (c) (1) This work is licensed under a Creative Commons Attribution 4.0 International License.

Read Full License

Version of Record: A version of this preprint was published at Indian Journal of Surgery on January 13th, 2022. See the published version at https://doi.org/10.1007/s12262-022-03286-7. 


\section{Abstract}

Aim:

The aim was to do a retrospective analysis and audit of our 90 days and in-hospital mortality after gastrointestinal and hepatopancreatic biliary surgery performed in our department and analyze factors predicting it.

Patients and methods:

All patients who underwent gastrointestinal and hepatopancreatic biliary surgery in our department in the last 3 years were evaluated for 90 days postoperative and in-hospital mortality and various factors affecting it. Categorical values were analyzed using the chi-square test or fisher's exact test wherever appropriate. Continuous variables were analyzed using the student t-test for parametric data and Mann Whitney $U$ test for nonparametric data after skewness and kurtosis analysis. Multivariate analysis was done using logistic regression analysis. A p-value less than 0.05 was considered statistically significant. Statistical analysis was done using SPSS version 23(IBM).

Results:

412 patients underwent gastrointestinal and hepatobiliary surgery in the last 3 years at our institute. Ninety days all-cause mortality was 5.8\%, all-cause in-hospital mortality was around $4.6 \% .90$ days mortality in elective and emergency surgeries were respectively $3.2 \%$ and $18 \%$. In-hospital mortality in elective and emergency surgeries were respectively $2.35 \%$ and $15.2 \%$. On multivariate analysis age, nontechnical complications, open surgery, and emergency surgery independently predicted 90 days mortality. On multivariate analysis age, acute kidney injury, non-procedural complications, and emergency surgeries independently predicted in-hospital mortalities.

Conclusion:

Age, non-technical complications, open surgery, and emergency surgeries are independently associated with 90 days mortality, and age, acute kidney injury, non-procedural complications, and emergency surgery independently predict in-hospital mortality.

\section{Introduction:}

Post-operative mortality is a very important criterion to determine the quality of care and mortality rates play a very important role in the risk-benefit analysis of any surgical procedure. [1] Overall postoperative mortality is decreased after the improvement of perioperative practices. However, complex gastrointestinal and hepatobiliary surgeries still have a major share in postoperative morbidity and mortality.[2] 
Surgeons are sometimes not comfortable discussing their outcome data and there is an increasing need for transparency in reporting surgical outcomes. A surgical mortality audit is an important tool to improve quality. There are some reports [3] that mortality audits improve surgical performances and make surgeons understand the role of better communication with the patients regarding real risk-benefit ratios and stop them from giving unrealistic hope to patients and their relatives.

This analysis aims to do a mortality audit of our data about in-hospital and 90 days mortality. We also evaluated various factors responsible for mortality via univariate and multivariate analysis.

\section{Patients And Methods:}

All patients who underwent gastrointestinal and hepatopancreatic biliary surgery in our department in the last 3 years were evaluated for 90 days postoperative and in-hospital mortality and various factors affecting it. We evaluated various factors like age, sex, type of surgery, emergency surgery. CDC grade of a wound, American society of anesthesiology grade, blood product used, operative time, technical or nontechnical complications, acute kidney injury, all types of leaks, bile leaks, anastomotic leaks, open or laparoscopic surgery, overall morbidity, and malignant diseases for their association with 90 days and inhospital mortalities.

\section{Statistical analysis:}

Categorical values were analyzed using the chi-square test or fisher's exact test wherever appropriate. Continuous variables were analyzed using the student $\mathrm{t}$-test for parametric data and Mann Whitney $\mathrm{U}$ test for nonparametric data after skewness and kurtosis analysis. Multivariate analysis was done using logistic regression analysis. A p-value less than 0.05 was considered statistically significant. Statistical analysis was done using SPSS version 23(IBM).

\section{Definitions:}

Mortality:

In-hospital, mortality was defined as any cause of mortality when a patient is admitted to the hospital. 90 days mortality was defined as any cause of mortality in 90 days post-operative period.

Acute kidney injury:

Acute kidney injury is defined according to acute kidney injury network classification [4, 5]. Any grade of acute kidney injury was considered significant.

Intraoperative hypotension: 
Intraoperative hypotension was defined as systolic arterial pressure below $80 \mathrm{mmHg}$, a decrease in systolic arterial pressure by $20 \%$ below baseline, or vasopressors requirement. [6]

Nontechnical and technical complications:

Non-technical complications were defined as perioperative complications related to patients' physiological health or comorbidities (e.g. acute kidney injury, ARDS, acute respiratory failure, cardiac complications, etc.), rather than to surgical procedures or techniques.

Technical complications were defined as perioperative complications related to surgical procedures or techniques (e.g. bleeding, leaks, sepsis, etc.). ARDS was defined according to the Berlin definition [7]. Acute myocardial infarction and postoperative left ventricular dysfunction were diagnosed as per cardiologists' opinion based on cardiac markers, electrocardiogram, and echocardiography. Pulmonary embolism was confirmed using a contrast-enhanced CT scan.

Centre of Disease Control Grading:

We also defined surgical wounds according to the Centre for Disease Control as clean (grade 1), cleancontaminated (grade 2), contaminated (grade 3), and dirty (grade 4).

Major and Nonmajor surgery:

We defined surgeries with literature proven negligible mortality rates like laparoscopic cholecystectomy, All hernia surgeries, laparoscopic appendicectomies as nonmajor surgeries, and other surgeries as major surgeries. All emergency surgeries were also defined as major surgeries.

\section{Results:}

412 patients underwent gastrointestinal and hepatobiliary surgery in the last 3 years at our institute. 90 days and in-hospital mortality:

Ninety days all-cause mortality was $5.8 \%$, all-cause in-hospital mortality was around $4.6 \% .90$ days mortality in elective and emergency surgeries were respectively $3.2 \%$ and $18 \%$. In-hospital mortality in elective and emergency surgeries were respectively $2.35 \%$ and $15.2 \%$.

222 surgeries were defined as major surgeries and 190 as nonmajor (including 143 laparoscopic cholecystectomies). 90 days mortalities and in-hospital mortality in elective major surgeries were respectively $6.7 \%$ and $4.8 \%$.

The type of surgery is mentioned in Table 1. 
Table 1

Type of surgeries performed.

\begin{tabular}{|ll|}
\hline Type of surgery & Number of Surgery \\
\hline $\begin{array}{l}\text { Upper } \\
\text { gastrointestinal } \\
\text { surgery }\end{array}$ & 19 \\
$\begin{array}{l}\text { Small bowel } \\
\text { surgery }\end{array}$ & 51 \\
\hline HPB surgery & $\begin{array}{l}233 \text { [43 cholecystectomies, 52 liver resections (including } 11 \text { extended } \\
\text { cholecystectomies with segment 4b5), 3 choledochal cyst resections, 20 liver } \\
\text { transplantations, 18 pancreatic resections ( } 9 \text { whipples, 5 distal pancreatectomies, } 1 \\
\text { enucleation, 3 lateral pancreaticojejunostomy. }\end{array}$ \\
\hline $\begin{array}{l}\text { Colorectal } \\
\text { Surgery }\end{array}$ & 60 \\
\hline Hernia & 47 \\
\hline
\end{tabular}

Univariate and multivariate analysis for 90 days and in-hospital mortality: [Table 2] 
Table 2

Univariate and multivariate analysis for 90 days and Inhospital mortality

\begin{tabular}{|c|c|c|c|c|}
\hline Factor & $\begin{array}{l}\text { Univariate } \\
\text { analysis } 90 \\
\text { days } \\
\text { mortality (p } \\
\text { value) }\end{array}$ & $\begin{array}{l}\text { Multivariate analysis } \\
90 \text { days mortality }\end{array}$ & $\begin{array}{l}\text { Univariate } \\
\text { analysis In- } \\
\text { hospital } \\
\text { mortality (p } \\
\text { value) }\end{array}$ & $\begin{array}{l}\text { Multivariate analysis } \\
\text { In-hospital mortality }\end{array}$ \\
\hline $\begin{array}{l}\text { Major surgery ( } \\
=222)\end{array}$ & $<0.0001$ & 0.994 & $<0.0001$ & 0.994 \\
\hline $\begin{array}{l}\text { Liver Resection } \\
\text { or transplant }(\mathrm{n}= \\
57)\end{array}$ & 0.123 & & 0.316 & \\
\hline $\begin{array}{l}\text { Malignant } \\
\text { disease }(n=75)\end{array}$ & 0.234 & & 0.761 & \\
\hline $\begin{array}{l}\text { Intra operative } \\
\text { hypotension }(n= \\
24)\end{array}$ & $<0.0001$ & $p=0.320$ & $<0.0001$ & $p=0.522$ \\
\hline $\begin{array}{l}\text { Acute Kidney } \\
\text { Injury }(n=24)\end{array}$ & $<0.0001$ & $p=0.271$ & $<0.0001$ & $\begin{array}{l}\mathrm{p}=0.022, \text { Odds ratio } \\
10.4,95 \% \\
\text { confidence interval } \\
1.42-70.80\end{array}$ \\
\hline $\begin{array}{l}\text { Morbidity (any } \\
\text { grade Clavein } \\
\text { Dindo } \\
\text { classification) ( } \\
=47 \text { ) }\end{array}$ & $<0.0001$ & $p=0.759$ & $<0.0001$ & $p=0.502$ \\
\hline $\begin{array}{l}\text { Open surgery ( } \mathrm{n} \\
=229)\end{array}$ & $<0.0001$ & 0.052 & 0.002 & $p=0.089$ \\
\hline $\begin{array}{l}\text { Non-technical } \\
\text { complications ( } \mathrm{n} \\
=33 \text { ) }\end{array}$ & $<0.0001$ & $\begin{array}{l}\mathrm{p}<0.0001, \text { Odds } \\
\text { ratio: } 61.15(95 \% \\
\text { confidence interval, } \\
9.19-406.73)\end{array}$ & $<0.0001$ & $\begin{array}{l}\mathrm{p}<0.0001, \text { Odds } \\
\text { ratio } 94.23,95 \% \\
\text { confidence interval } \\
8.47-1048.23\end{array}$ \\
\hline $\begin{array}{l}\text { Emergency } \\
\text { surgery }(n=72)\end{array}$ & $<0.0001$ & $\begin{array}{l}\mathrm{p}=0.002, \text { Odds ratio: } \\
28.20(95 \% \\
\text { confidence interval, } \\
3.34-237.99)\end{array}$ & $<0.0001$ & $\begin{array}{l}\mathrm{p}=0.013, \text { Odds ratio } \\
16.52,(95 \% \\
\text { confidence interval } \\
1.81-150.42)\end{array}$ \\
\hline $\begin{array}{l}\text { Colorectal } \\
\text { surgery }(n=60)\end{array}$ & 0.139 & & 0.043 & $p=0.208$ \\
\hline $\begin{array}{l}\text { Small bowel } \\
\text { surgery }(n=48)\end{array}$ & 0.751 & & 1.0 & \\
\hline $\begin{array}{l}\text { Upper GI surgery } \\
(n=18)\end{array}$ & 0.282 & & 0.199 & \\
\hline $\begin{array}{l}\text { HPB surgery }(n= \\
232)\end{array}$ & 0.298 & & 0.239 & \\
\hline
\end{tabular}




\begin{tabular}{|c|c|c|c|c|}
\hline Factor & $\begin{array}{l}\text { Univariate } \\
\text { analysis } 90 \\
\text { days } \\
\text { mortality ( } p \\
\text { value) }\end{array}$ & $\begin{array}{l}\text { Multivariate analysis } \\
90 \text { days mortality }\end{array}$ & $\begin{array}{l}\text { Univariate } \\
\text { analysis In- } \\
\text { hospital } \\
\text { mortality ( } p \\
\text { value) }\end{array}$ & $\begin{array}{l}\text { Multivariate analysis } \\
\text { In- hospital mortality }\end{array}$ \\
\hline $\begin{array}{l}\text { Hernia and } \\
\text { others }(n=47)\end{array}$ & 0.093 & & 0.148 & \\
\hline $\begin{array}{l}\text { Overall leaks }(n= \\
18)\end{array}$ & 0.08 & & 0.581 & \\
\hline $\begin{array}{l}\text { Anastomotic } \\
\text { leaks }(n=13)\end{array}$ & 0.034 & $p=0.514$ & 0.465 & \\
\hline Bile leak $(n=13)$ & 0.004 & $p=0.172$ & 0.107 & \\
\hline $\begin{array}{l}\text { Technical } \\
\text { complications ( } \mathrm{n} \\
=14 \text { ) }\end{array}$ & 0.041 & $p=0.559$ & 0.489 & \\
\hline Age & 0.037 & $\begin{array}{l}\mathrm{p}=0.022, \text { Odds ratio: } \\
1.072(95 \% \\
\text { confidence interval, } \\
1.01-1.13)\end{array}$ & 0.029 & $\begin{array}{l}P=0.019, \text { Odds } \\
\text { ratio: } 1.094,95 \% \\
\text { confidence interval } \\
1.015-1.179\end{array}$ \\
\hline $\begin{array}{l}\text { CDC grade of } \\
\text { surgery }\end{array}$ & $<0.0001$ & $p=0.054$ & $<0.0001$ & $p=0.138$ \\
\hline $\begin{array}{l}\text { Blood product } \\
\text { use }\end{array}$ & $<0.0001$ & $p=0.817$ & $<0.0001$ & $p=0.181$ \\
\hline ASA & $<0.0001$ & $p=0.986$ & $<0.0001$ & $p=0.569$ \\
\hline Operative time & $<0.0001$ & $p=0.261$ & 0.002 & $p=0.653$ \\
\hline
\end{tabular}

On univariate analysis, Major surgery, age, CDC grade of wound classification, Intraoperative hypotension, acute kidney injury, morbidity after surgery, open surgery, nonprocedural complications, number of blood products used, American society of anesthesiology grading, emergency surgery, operative time, all leaks, all procedural complications, anastomotic leaks, and bile leaks were associated with 90 days mortality. On multivariate analysis age, nontechnical complications, and emergency surgery independently predicted 90 days mortality. On univariate analysis, Major surgery, Age, CDC grade of wound classification, Intraoperative hypotension, acute kidney injury, morbidity after surgery, open surgery, nonprocedural complications, number of blood products used, American society of anesthesiology grading, emergency surgery, operative time, colorectal surgeries, and bile leaks were associated with inhospital mortality. On multivariate analysis age, acute kidney injury, non-procedural complications, and emergency surgeries independently predicted in-hospital mortalities.

90 days survival analysis: 
We also analyzed factors affecting survival via cox regression analysis. It also showed age, non-technical complications, and emergency surgery was associated with worse survival over 90 days. [Table 3]. Figure 1 shows Kaplan Meier survival curved comparing 90 days survival in patients who developed nontechnical complications vs patients who did not develop them.

Table 3

Multivariate cox regression analysis for 90 days survival.

\begin{tabular}{|c|c|c|c|}
\hline Factors & $p$ value & $\begin{array}{l}\text { Hazard } \\
\text { ratio }\end{array}$ & $\begin{array}{l}95 \% \text { confidence interval of hazard } \\
\text { ratio }\end{array}$ \\
\hline Major Hepatectomy & 0.912 & & \\
\hline Intraoperative hypotension & 0.647 & & \\
\hline Acute Kidney Injury & 0.823 & & \\
\hline Overall morbidity & 0.511 & & \\
\hline Open Surgery & 0.102 & & \\
\hline Nontechnical complications & $<.0001$ & 20.075 & $5.241-76.890$ \\
\hline Blood products & 0.972 & & \\
\hline $\begin{array}{l}\text { American Society of Anesthesiology } \\
\text { score }\end{array}$ & 0.539 & & \\
\hline Operative time & 0.593 & & \\
\hline Emergency Surgery & 0.009 & 6.879 & $1.618-29.25$ \\
\hline Anastomotic leak & 0.410 & & \\
\hline Bile leak & 0.602 & & \\
\hline Technical complications & 0.445 & & \\
\hline CDC grade of wound & 0.061 & & \\
\hline Age & 0.041 & 1.045 & $1.002-1.090$ \\
\hline
\end{tabular}

\section{Discussion:}

Perioperative mortality is one of the most important problems the surgical community must face.

Perioperative mortality ranges from $0.1 \%$ to as high as $27-30 \%$, depending on the type of surgery. [8, 9]. Gastrointestinal and hepatobiliary surgery is technically demanding procedures and has among the highest perioperative mortality rates. $[10,11,12]$. Another issue is surgeons rarely audit their mortality data scientifically and in-process rarely know what factors might be responsible for poor outcomes in their patients. 
This study aimed to do a mortality audit for patients operated for gastrointestinal and hepatobiliary surgeries in our department and study factors responsible for 90 days and in-hospital mortality.

Our elective 90 days and in-hospital mortality rates after elective surgeries were around $3.2 \%$ and $2.3 \%$ respectively and $18 \%$ and $15.2 \%$ respectively, which is comparable to what Sørensen et al. [12] described in their study. They showed 30 days mortality of $2.8 \%$ and $13 \%$ respectively in elective and emergency surgeries.

Our overall 90 days and in-hospital mortality rates were $5.6 \%$ and $4.2 \%$ which were comparable to published literature. [13].

We chose to study 90 days mortality instead of 30 days mortality as mayo et al [14] described 90 days mortality should be the standard criteria to describe perioperative mortality.

As we have described in results various factors were associated with 90 days and in-hospital mortality but on multivariate analysis nontechnical complications, age and emergency surgery independently predicted both 90 days and in-hospital mortality. Post-operative acute kidney injury was associated with in-hospital mortality independently however it was not associated with 90 days mortality after multivariate analysis which may imply that patients who recovered from post-operative acute kidney injury did well subsequently.

90 days mortality and in-hospital mortality in major surgeries in our series were $6.7 \%$ and $4.8 \%$ respectively. Major surgery was not independently associated with 90 days or in-hospital mortality after multivariate analysis. Heyer et al [15] in their recently published study consisting of a large cohort of complex gastrointestinal surgeries showed textbook outcomes are increased over time, they showed 90 days mortality of around $9.2 \%$ in a cohort of more than 31000 patients operated between 2014-2016. In our series complex, gastrointestinal surgery for malignancy showed similar results of $9.3 \% 90$ days mortality and $5.3 \%$ in-hospital mortality. However, surgery for the malignant disease was not associated with 90 days or in-hospital mortality.

Type of surgery like liver resections or transplants, HPB surgery, upper gastrointestinal surgery, small intestinal surgeries, colorectal surgeries, hernia, and other surgeries were not associated with 90 days or in-hospital mortality. Colorectal surgery was not associated with 90 days mortality, it was associated with in-hospital mortality on univariate analysis but failed to show association on multivariate analysis.

Surgeons are always worried about the technical aspects of surgery, although very few studies have been carried out that looked at the impact of non-technical complications on perioperative mortality. There are various perioperative complications, which are not related to surgical techniques and depend on many factors, such as patients' preoperative conditions perioperative course of anesthesia, pathophysiologic response to surgical stress, etc. These complications can include, but are not limited to, acute kidney injury, ARDS, postoperative delirium, myocardial infarction, and postoperative acute left ventricular dysfunction. These complications contribute significantly to overall mortality. [16, 17] 
In our series, nontechnical complications were independently associated with 90 days and in-hospital mortality after multivariate logistic regression analysis and their strength of associated was very high with odds ratios of 61.15 and 94.23 respectively for 90 days and in-hospital mortality, suggesting the need to concentrate on preoperative, intraoperative, and postoperative critical care management to prevent and treat such complications. Pre and intraoperative factors like CDC grading of wound classification, American society of anesthesia score, number of blood transfusions, duration of surgery predicted 90 days, and in-hospital mortality on univariate analysis but failed to show independent association on multivariate analysis and they might have some role to play in the development of nontechnical complications.

Technical complications like intraoperative bleeding, anastomotic leaks, or bile leaks have no association with in-hospital mortality. Anastomotic leaks and bile leaks had an association with 90 days mortality on univariate analysis but had no independent association after multivariate analysis. It again showed the importance of perioperative critical care management to reduce mortality.

Age and Emergency surgeries also predicted both 90 days and in-hospital mortality independently. However, Age had weak strength of association with an odds ratio of 1.07 and 1.09 for 90 days and inhospital mortality respectively.

Logistic regression looked at 90 days mortality on multivariate analysis, we also analyzed time to the event by cox regression analysis which showed similar results, and age, emergency surgeries, and nontechnical complications were associated with worse survival over 90 days. Figure 1 showed on Kaplan Meier analysis non-technical complications were associated with significantly worse 90 days survival.

There are certain limitations of this study, as being a retrospective analysis there can be inherent limitations of retrospective analysis like selection bias. However, data was maintained prospectively. There can be other factors affecting mortality that could not be included in the analysis. The sample size was small as can be seen from the wider confidence interval. Our unit being predominantly Hepatopancreatic biliary surgery (HPB) unit in this analysis HPB surgeries outnumbered the other surgeries. The strength of the study is that it is one of the few studies showing strong strength of association with postoperative nontechnical complications with postoperative mortality.

In conclusion, Age, non-technical complications, open surgery, and emergency surgeries are independently associated with 90 days mortality, and age, acute kidney injury, non-procedural complications, and emergency surgery independently predicts in-hospital mortality.

\section{Declarations}

Ethical clearance: obtained from hospital ethics committee.

Competing interests: The authors declare no competing interests. 


\section{References}

1. Fecho K, Lunney AT, Boysen PG, Rock P, Norfleet EA. Postoperative mortality after inpatient surgery: Incidence and risk factors. Ther Clin Risk Manag. 2008;4(4):681-688. doi:10.2147/tcrm.s2735

2. Jakobson T, Karjagin J, Vipp L, et al. Postoperative complications and mortality after major gastrointestinal surgery. Medicina (Kaunas). 2014;50(2):111-117.

3. Lui CW, Boyle FM, Wysocki AP, et al. How participation in surgical mortality audit impacts surgical practice. BMC Surg. 2017;17(1):42. Published 2017 Apr 19. doi:10.1186/s12893-017-0240-z

4. Mehta RL, Kellum JA, Shah SV et al (2007) Acute Kidney Injury Network: report of an initiative to improve outcomes in acute kidney injury. Crit Care 11(2):R31

5. Kellum JA (2015) Diagnostic criteria for acute kidney injury: present and future. Crit Care Clin $31(4): 621-632$.

6. Bijker JB, van Klei WA, Kappen TH, et al. Incidence of intraoperative hypotension as a function of the chosen definition: literature definitions applied to a retrospective cohort using automated data collection. Anesthesiology 2007. 107(2):213-220.

7. ARDS Defi nition Task Force, Ranieri VM, Rubenfeld GD, et al. Acute Respiratory Distress Syndrome: The Berlin Defi nition. JAMA. 2012; 307(23): 2526-2533.

8. Ng-Kamstra JS, Arya S, Greenberg SLM, Kotagal M, et al.Perioperative mortality rates in low-income and middle-income countries: a systematic review and meta-analysis. BMJ Glob Health. 2018; 3(3): e000810. doi:10.1136/bmjgh-2018-000810.

9. Marino MV, Mituś JW, Vaccarella G, et al. Complications profile after robotic pancreatic surgery. Państwo i Społeczeństwo. 2020; 2: 51-63.doi: 10.34697/2451-0858-pis-2020-1-004.

10. Csikesz NG, Simons JP, Tseng JF,et al. Surgical specialization and operative mortality in hepatopancreatico-biliary (HPB) surgery. J Gastrointest Surg. 2008;12(9): 1534-1539. doi:10.1007/s11605008-0566-z.

11. Kneuertz PJ, Pitt HA, Bilimoria KY, et al Risk of morbidity and mortality following hepato-pancreatobiliary surgery.J Gastrointest Surg. 2012; 16(9): 1727-1735. doi:10.1007/s11605-012-1938-y.

12. Sørensen LT, Malaki A, Wille-Jørgensen P, et al. Risk factors for mortality and postoperative complications after gastrointestinal surgery. J Gastrointest Surg. 2007; 11(7):903-910.

13. Ray S, Mehta NN, Mangla V, et al. A Comparison Between the Comprehensive Complication Index and the Clavien-Dindo Grading as a Measure of Postoperative Outcome in Patients Undergoing Gastrointestinal Surgery-A Prospective Study. J Surg Res. 2019;244:417-424.

14. Mayo SC, Shore AD, Nathan $\mathrm{H}$, et al. Refining the definition of perioperative mortality following hepatectomy using death within 90 days as the standard criterion. HPB (Oxford). 2011;13(7):473482.

15. Hyer JM, Beane JD, Spolverato G, et al. Trends in Textbook Outcomes over Time: Are Optimal Outcomes Following Complex Gastrointestinal Surgery for Cancer Increasing? [published online ahead of print, 2021 Sep 10]. J Gastrointest Surg. 2021;10.1007/s11605-021-05129-4. 
16. Miskovic A, Lumb AB. Postoperative pulmonary complications. Br J Anaesth. 2017; 118(3): 317334. doi: 10.1093/bja/aex002.

17. Gameiro J, Fonseca JA, Neves $M$, et al. Acute kidney injury in major abdominal surgery: incidence, risk factors, pathogenesis, and outcomes. Ann Intensive Care. 2018; 8(1): 22. doi:10.1186/s13613018-0369-7.

18. Yamamoto T, Takahashi S, Ichihara K, et al. How do we understand the disagreement in the frequency of surgical site infection between the CDC and Clavien-Dindo classifications?. J Infect Chemother. 2015;21(2):130-133.

Figures

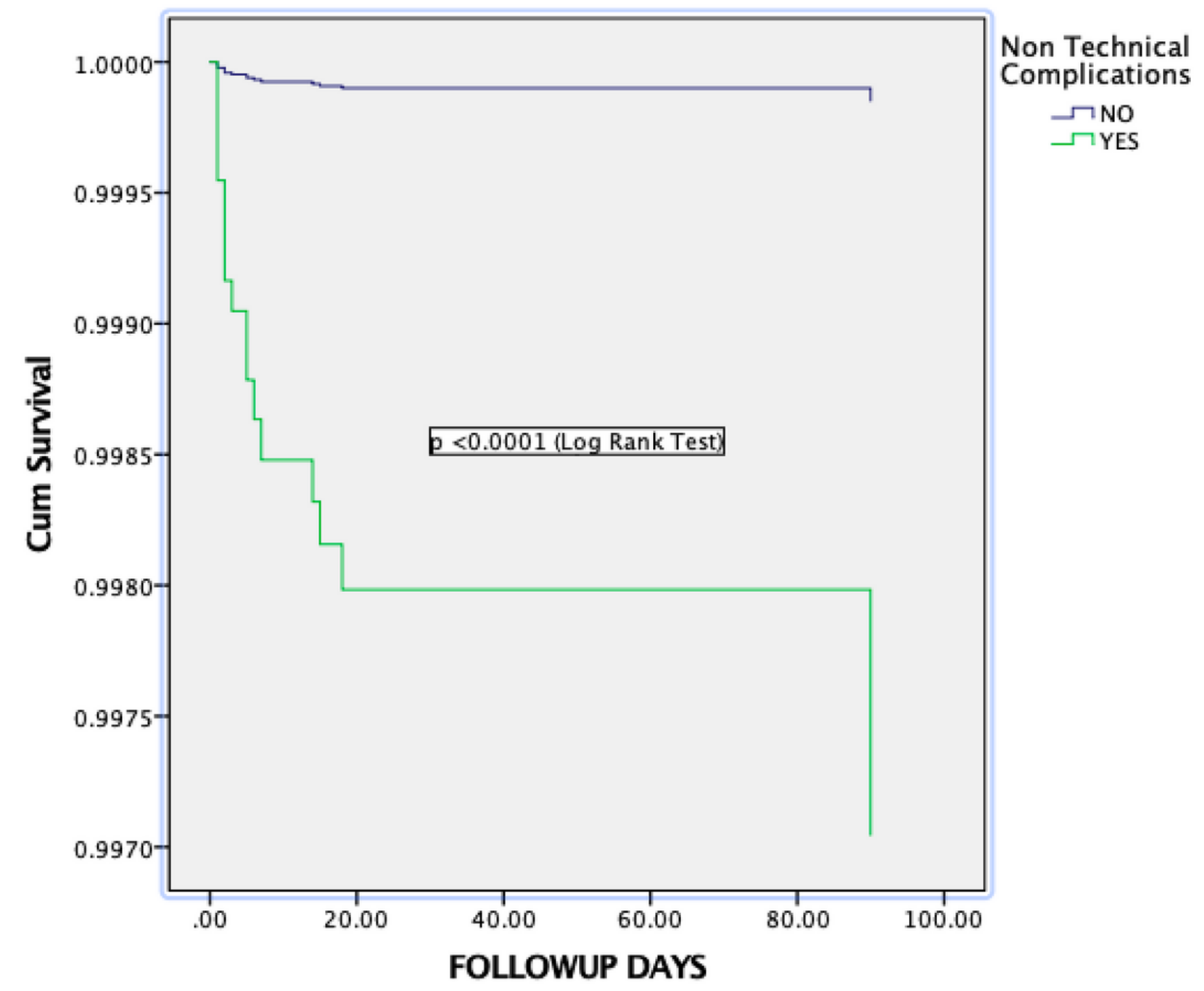

Figure 1 
Kaplan Meier Curve with log rank test showing significant difference in 90 days survival between patients who developed nontechnical complications vs who did not develop. 